\title{
Transcriptomic Profiling of Acute Cold Stress-Induced Disease Resistance (SIDR) Genes and Pathways in the Grapevine Powdery Mildew Pathosystem
}

\author{
William A. Weldon, ${ }^{1}$ Cal D. Palumbo, ${ }^{2}$ Alisson P. Kovaleski, ${ }^{3}$ Kiersten Tancos, ${ }^{1}$ David M. Gadoury, ${ }^{1}$ \\ Michael V. Osier, ${ }^{2}$ and Lance Cadle-Davidson ${ }^{1,3,+}$ \\ ${ }^{1}$ Section of Plant Pathology and Plant-Microbe Biology, Cornell AgriTech, Cornell University, Geneva, NY 14456, U.S.A. \\ 2 Thomas H. Gosnell School of Life Sciences, Rochester Institute of Technology, Rochester, NY 14623, U.S.A. \\ ${ }^{3}$ United States Department of Agriculture-Agricultural Research Service Grape Genetics Research Unit, Geneva, NY 14456, U.S.A.
}

Accepted 21 September 2019.

Temperatures from 2 to $8^{\circ} \mathrm{C}$ transiently induce quantitative resistance to powdery mildew in several host species (cold stress-induced disease resistance [SIDR]). Although cold SIDR events occur in vineyards worldwide an average of 14 to 21 times after budbreak of grapevine and can significantly delay grapevine powdery mildew (Erysiphe necator) epidemics, its molecular basis was poorly understood. We characterized the biology underlying the Vitis vinifera cold SIDR phenotypewhich peaks at $24 \mathrm{~h}$ post-cold (hpc) treatment and results in a 22 to $28 \%$ reduction in spore penetration success-through highly replicated ( $n=8$ to 10) RNA sequencing experiments. This phenotype was accompanied by a sweeping transcriptional downregulation of photosynthesis-associated pathways whereas starch and sugar metabolism pathways remained largely unaffected, suggesting a transient imbalance in host metabolism and a suboptimal target for pathogen establishment. Twenty-six cold-responsive genes peaked in their differential expression at the 24-hpc time point. Finally, a subset of genes associated with nutrient and amino acid transport accounted for four of the eight most downregulated transcripts, including two nodulin 1A gene precursors, a nodulin MtN21 precursor, and a Dynein light chain 1 motor protein precursor. Reduced transport could exacerbate localized nutrient sinks that would again be transiently suboptimal for pathogen growth. This study links the transient cold SIDR phenotype to underlying transcriptional changes and provides an experimental framework and library of candidate genes to further explore

W. A. Weldon and C. D. Palumbo contributed equally to this work.

${ }^{\dagger}$ Corresponding author: L. Cadle-Davidson;

lance.cadledavidson@ars.usda.gov

Funding: The United States Department of Agriculture (USDA)Agricultural Research Service CRIS project 8060-21220-007-00-D and USDA-National Institute of Food and Agriculture Specialty Crop Research Initiative award number 2017-51181-26829 provided funding for this project.

*The $\boldsymbol{e}$-Xtra logo stands for "electronic extra" and indicates that six supplementary figures and two supplementary tables are published online.

The author(s) declare no conflict of interest.

This article is in the public domain and not copyrightable. It may be freely reprinted with customary crediting of the source. The American Phytopathological Society, 2020. cold SIDR in several systems, with an ultimate goal of identifying novel breeding or management targets for reduced disease.

Keywords: abiotic stress and obligate biotroph interactions, leaf disk, low temperature, mechanisms of pathogenicity, photosynthesis, physiology, transcriptomic

Environmental variables are often key quantifiable drivers of successful pathogen infection and, as such, are widely used as the inputs driving disease forecasting models (Aćimović and Rosenberger 2018; Golnaraghi et al. 2018; Small et al. 2015; Thomas et al. 1994). Environmental conditions are particularly significant in the case of obligately biotrophic pathogens, which must balance the covert acquisition of host nutrients with the continued viability of host plant tissue. Any source of environmental stress that alters host physiology then has the theoretical potential to also impact the obligately biotrophic parasite. Powdery mildews occupy a unique niche among obligate biotrophs because almost the entirety of the fungus's mycelial growth is external to the host. Consequently, the pathogen is also highly and directly sensitive to environmental inputs such as drought stress (Achuo and Prinsen 2006; Mortensen and Gislerød 2005), nutrient stress (Wiese et al. 2005), prolonged precipitation (Aust and Hoyningen-Huene 1986), or acute overnight cold events (Moyer et al. 2016, 2010).

Acute cold stress-induced disease resistance (SIDR) is a recently described phenomenon in the grapevine powdery mildew pathosystem (involving Vitis spp. and Erysiphe necator). Cold SIDR is initiated by preinfection exposure of the grapevine to brief cold events ( 2 to $8^{\circ} \mathrm{C}$ for one or more hours), typically occurring overnight, inducing a transient reduction in powdery mildew susceptibility of approximately 20\%. This induced resistance peaks $24 \mathrm{~h}$ after the cold event and returns to a basal level within $48 \mathrm{~h}$ (Moyer et al. 2010). Such brief overnight cold events have been documented as common occurrences during the early spring growing season in both warm- and cold-climate viticultural regions, including New York, California, Australia, and Germany (Moyer et al. 2010). In addition to preinfection cold SIDR, acute cold events that occur after $E$. necator infection (in the presence of both the grape host and pathogen) significantly reduce subsequent $E$. necator growth, including prolonged latent period and reduced sporulation density (Moyer et al. 2010, 2016). Even the most susceptible Vitis vinifera grapevine cultivars such as Chardonnay or Riesling exhibit a significant cold SIDR response (Moyer et al. 2010). 
Although the cold SIDR phenotype has been described, host gene expression changes underlying the induction of resistance remain poorly understood. In contrast, much is known about transient gene expression responses to low temperatures in general. The cascade of gene expression leading to lowtemperature responses starts with the perception of temperature by tissues through increased rigidity of membranes and $\mathrm{Ca}^{2+}$ signaling (Bahuguna and Jagadish 2015; Horváth et al. 1998). Low-temperature perception leads to the expression of inducer of $C$-repeat-binding factor $(C B F)$ expression (ICE) genes, resulting in upregulation of dehydration-responsive elementbinding $1(D R E B 1) / C B F)$ genes (Chinnusamy et al. 2003). $D R E B 1 / C B F$ transcription factors then promote the expression of cold-regulated (COR) and cold-induced (KIN) genes (Chinnusamy et al. 2003; Yamaguchi-Shinozaki and Shinozaki 2006). Expression levels of $C B F$ genes increase within a few hours of cold stress, whereas $C O R$ and $K I N$ genes are upregulated after 12 to $24 \mathrm{~h}$ (Chinnusamy et al. 2003). In grapevine leaves, $C B F 1$ and $C B F 2$ have an increase in transcript levels within hours of cold stress $\left(4^{\circ} \mathrm{C}\right)$, whereas $C B F 3$ is upregulated after multiple days, where the response is enhanced in younger compared with older leaves (Xiao et al. 2006). Under freeze stress $\left(-3^{\circ} \mathrm{C}\right)$, upregulation of ethylene signaling and abscisic acid (ABA) synthesis and signaling occurs, whereas $48 \mathrm{~h}$ of cold stress $\left(4^{\circ} \mathrm{C}\right)$ only results in upregulation of ethylene signaling (Londo et al. 2018). Both freeze and cold stresses promote downregulation of genes related to the production of soluble sugars and upregulation of starch synthesis enzymes (Londo et al. 2018). Multiple transcription factor families that are associated with both biotic and abiotic stresses are differentially regulated under cold stress, such as $A P 2 / E R F$, WRKY, and NAC (Londo et al. 2018; Wang et al. 2014; Xin et al. 2013).

A recent review of the acute cold SIDR phenomenon (Moyer et al. 2016) posed possible molecular explanations for the induced resistance response, which can be summarized in the following three hypotheses: (i) grapevine foliage becomes less photosynthetically active, temporarily reducing the host's ability to produce usable energy for the pathogen-a temporary transcriptional downregulation of photosynthesis-associated gene pathways would be expected in this case; (ii) similar to an ontogenic resistance response (Asalf et al. 2014; Ficke et al. 2002), the grape tissue transitions (in this case temporarily) from a net carbon consumer to a net carbon source-one would expect to see expression changes reflecting continued or upregulated photosynthetic activity and upregulation of genes associated with sugar export; and (iii) the cold SIDR phenotype is actuated through regulatory changes in plant hormone signaling, especially those associated with $\mathrm{ABA}$ and gibberellic acid, and through induction of abiotic stress pathways such as the cold shock regulation complex ICE-CBF.

Here, we aim to confirm the in vitro biology of cold SIDR and use the corresponding host tissue to test the above three hypotheses as alternatives to a null hypothesis that there is no significant change in host gene regulation associated with the cold SIDR phenotype. A time-course experiment was used to decouple the general transcriptional changes that occur in response to cold with different dynamics from the transcriptional changes specifically associated with the cold SIDR response that restrains E. necator infection.

\section{RESULTS}

\section{Cold SIDR and ontogenic resistance.}

Penetration success percentages were significantly different between the control and cold-treated samples at each leaf position $(\alpha=0.05)$ (Fig. 1A). Furthermore, leaf age affected the penetration success percentages regardless of cold treatment.
As expected within the control group, penetration success percentages were generally higher on younger leaves compared with older, ontogenically resistant leaves, with significantly reduced penetration success on leaf position four relative to the three younger positions, by approximately 20 to $25 \%(\alpha=0.05)$ (Fig. 1A). Similar magnitudes and trends were observed within the cold-treatment group, with the factors ontogenic resistance and cold SIDR each reducing penetration success by approximately 20 to $25 \%$ independent of the other factor (Fig. 1A).

\section{Detached grape leaves versus leaf disks.}

No significant differences were detected in penetration success percentages between detached leaves and leaf disks at any of three times $(0,24$, or $48 \mathrm{~h})$ after cutting of the leaf disk $(\alpha=$ 0.05) (Fig. 1B). Cutting leaves into disks did not affect penetration success; therefore, subsequent experiments were executed on leaf disks.

\section{Grape cold SIDR time course experiment.}

Three cold SIDR time course experiments were conducted to identify the time between a cold event and induced resistance to subsequent inoculation with $E$. necator. Third-node $V$. vinifera 'Chardonnay' leaves representative of those produced in our greenhouse system had lamina lengths, on average, $58.1 \%$ of the lamina length of the fully expanded leaf of the given vine, indicating that the third-node leaves used for this experiment were likely to be undergoing the sink-to-source transition (Merry et al. 2013). Consistent with previous reports (Moyer et al. 2010), in all three experiments, the 24-h post-cold (hpc) time point had a significant reduction in E. necator penetration

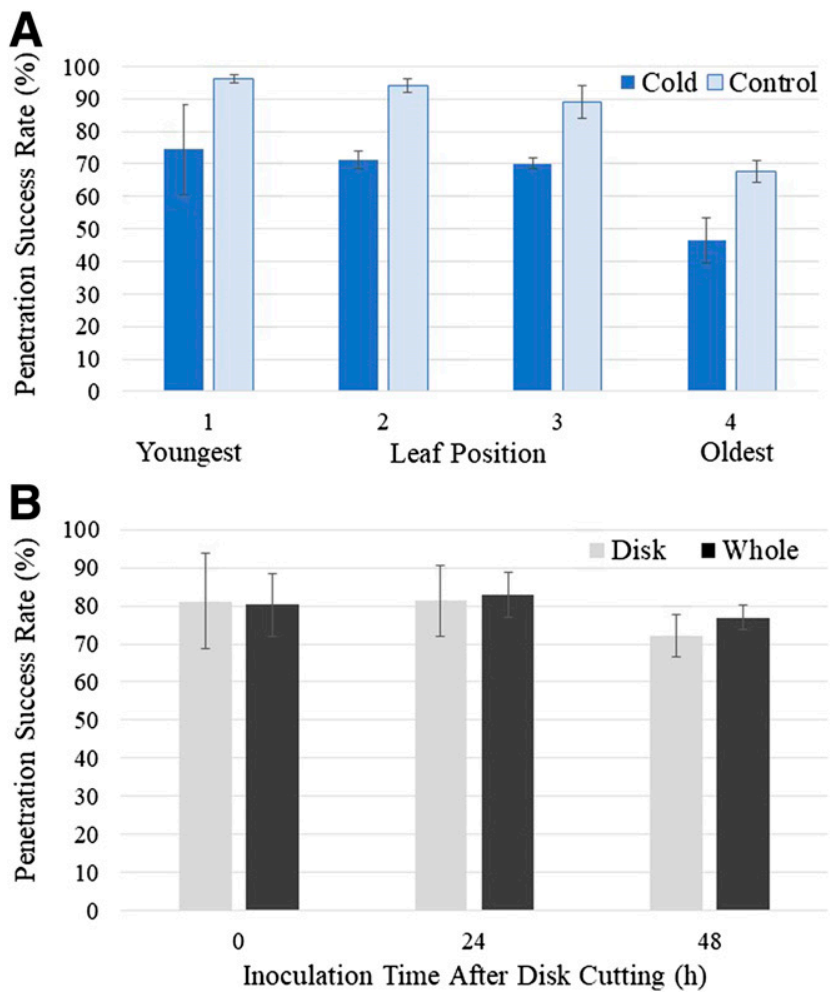

Fig. 1. Effects of ontogenic resistance, cold stress-induced disease resistance, and leaf disk cutting on penetration success of Erysiphe necator conidia on Vitis vinifera 'Chardonnay' detached leaves. A, Leaf position reflects the position of a leaf relative to the apex of a grapevine shoot for cold-treated leaves (dark bars) maintained at $4^{\circ} \mathrm{C}$ for $4 \mathrm{~h}$ and nontreated control leaves (light bars). B, Leaf disks (light bars) were inoculated at 0 , 24 , and $48 \mathrm{~h}$ after cutting in comparison with inoculated whole leaves (dark bars). Error bars indicate standard deviation. 
success (Table 1). As such, differential expression at this time point was the primary focus in the downstream $3^{\prime}$ RNA sequencing (RNAseq) analyses. In all three experimental repeats, one or two of the 10 leaf disks lacked the cold SIDR phenotype, having penetration success percentages similar to the nontreated control (NTC) group. To account for this expected response, one disk from each leaf was assigned to each treatment and tracked; the random effect "leaf number" in the generalized mixed-effects model accounted for 46.1 to $47.7 \%$ of the random variation observed in the dataset. As in previous publications (Moyer et al. 2010, 2016), no treatment reproducibly affected E. necator colony success (Supplementary Table S1). Therefore, RNAseq differential expression profiling analyses using susceptibility as a predictor were based on conidia penetration success reductions.

\section{3' RNAseq analysis.}

Preprocessing, quality analysis, and alignment. The mean sequencing depth per sample replicate prior to quality control (QC) was 5.3 million (M) reads, which reduced to $4.7 \mathrm{M}$ reads following the multistep QC (an average of $69.6 \mathrm{M}$ clean reads per treatment across three experiments). The minimum read depth for a single leaf disk was $1.8 \mathrm{M}$ reads. Principal component analysis suggested that experiment was a significant factor in gene expression, with samples from experiments 2 and 3 clustering more closely than samples from experiment 1 (Supplementary Fig. S1). Gene count outlier analysis showed that seven samples (four from experiment 1) had 90 or more genes flagged as having outlier counts compared with the other treatment samples (Supplementary Fig. S2). Based on these results, experiment 1 plus three samples from the other two

Table 1. Percentage of reduction in spore penetration success (relative to nontreated control [NTC], which ranged from 51.4 to $74.3 \%$ ) at 12 to $48 \mathrm{~h}$ post-cold (hpc) treatment, in three independent experiments $(\text { Exp })^{\mathrm{z}}$

\begin{tabular}{lcccccc}
\hline Treatment & Exp 1 & $\boldsymbol{P}$ value & Exp 2 & $\boldsymbol{P}$ value & Exp 3 & $\boldsymbol{P}$ value \\
\hline NTC & $\mathrm{a}$ & $\ldots$ & $\mathrm{ad}$ & $\ldots$ & $\mathrm{ad}$ & $\ldots$ \\
$12 \mathrm{hpc}$ & $23.8 \mathrm{bc}$ & 0.041 & $\mathrm{a}$ & $\ldots$ & $\mathrm{cd}$ & $\ldots$ \\
$24 \mathrm{hpc}$ & $25.1 \mathrm{bc}$ & 0.028 & $28.4 \mathrm{bc}$ & 0.018 & $22.3 \mathrm{bc}$ & 0.048 \\
$36 \mathrm{hpc}$ & $25.3 \mathrm{bc}$ & 0.027 & $\mathrm{ac}$ & $\ldots$ & $\mathrm{ad}$ & $\ldots$ \\
$48 \mathrm{hpc}$ & $\mathrm{ac}$ & $\ldots$ & $\mathrm{cd}$ & $\ldots$ & $\mathrm{cd}$ & $\ldots$ \\
\hline
\end{tabular}

z A generalized mixed-effects model was generated with Tukey's correction for multiple comparisons $(\alpha=0.05)$, where penetration success $\sim$ treatment + (1 leaf). Percentage of reduction in spore penetration success relative to the NTC group is provided for treatments significantly different than the NTC. Within each experiment, treatments with the same letter were not significantly different after correction for multiple comparisons. $P$ values are provided for treatments significantly different than the NTC. experiments with gene count outliers were removed from downstream analysis, still retaining nine or 10 biological replicates sequenced per treatment time point.

Following STAR software read alignment, the mean percentage of uniquely mapped reads was $90.1 \%$, with a minimum of $87.1 \%$. Samples had a mean of 3,059,445 reads uniquely assigned to gene positions and counted, with a minimum of 1,100,654 and maximum of 5,896,608 (Supplementary Fig. S3). This resulted in a mean of $45.9 \mathrm{M}$ reads assigned and counted per treatment across all replicates and experiments.

Cluster and pathway enrichment analyses. The three models listed in Table 2 identified 2,655 differentially expressed genes (DEGs) (Fig. 2A), which formed 13 significant gene clusters (Supplementary Figs. S4 and S5). Only two gene clusters had their most extreme $\log _{2}$ fold change $\left(\mathrm{L}_{2} \mathrm{FC}\right)$ coinciding with cold SIDR phenotype at $24 \mathrm{hpc}$. Gene cluster $3 \mathrm{had}$ a mean $\mathrm{L}_{2} \mathrm{FC}$ increase of 0.76 and gene cluster 2 had a mean $\mathrm{L}_{2} \mathrm{FC}$ decrease of -0.98 (Supplementary Fig. S6). These two gene clusters were subjected to pathway enrichment analysis to consider directional transcriptional changes of entire pathways that may drive the quantitative cold SIDR phenotype. Relevant pathways of clusters 2 and 3 are summarized in Table 3. For gene cluster 2 (42 downregulated genes), 20 genes were associated with metabolism, 9 with the electron transport chain and signaling, and 8 had an Arabidopsis thaliana homolog characterized as a COR gene (Thomashow 1999) (Supplementary Table S2). Of the 78 genes upregulated in gene cluster 3 , there were 10 amino acid and nucleic acid metabolism associated genes, five starch and sugar metabolism genes, 13 cell signaling genes, and $18 \mathrm{~A}$. thaliana homologous genes with a COR function (Supplementary Table S2).

Of the 2,655 DEGs output in the three statistical models (Table 2), 197 genes were specifically reported in the susceptibility model alone, or in overlap with either one or both of the other models (Treatment and Time ${ }^{2}$ ). As such, they each followed a regulation pattern peaking at $24 \mathrm{hpc}$ (Fig. 2B). These 197 genes were reviewed individually for their relevance to any of the three alternative cold SIDR hypotheses (Table 4), as well as for any additional trends in transcriptional regulation that pose additional alternative explanations for the cold SIDR phenotype (Table 5).

\section{Mapping results to hypotheses.}

Hypothesis 1. Cold SIDR results from a decreased photosynthetic rate. Specific to cold SIDR, gene cluster 2 showed broad and significant downregulation of photosynthesis-associated gene pathways (Table 3). However, in the subset of DEGs overlapping between models 1 and 2 , there was only one

Table 2. Design formulas used to identify the complete set of genes responding to cold treatment, whether generally over time or specifically in association with altered susceptibility due to cold stress-induced disease resistance ${ }^{\mathrm{Z}}$

\begin{tabular}{lll}
\hline Shorthand, model & \multicolumn{1}{c}{ Design formula } & Purpose \\
\hline Treatment & $\sim$ Disk number + Treatment & $\begin{array}{c}\text { Identify genes that changed between treatment groups, controlling } \\
\text { for leaf variability } \\
\text { Full }\end{array}$ \\
$\quad \sim$ Disk number & $\ldots$ \\
Reduced & $\sim$ Disk number + Circadian Rhythm + & $\begin{array}{c}\text { Identify genes that changed by percent susceptibility, controlling for } \\
\text { leaf variability and circadian rhythm }\end{array}$ \\
Full & Susceptibility & $\ldots$ \\
Reduced $_{\text {Time }}^{2}$ & $\sim$ Disk number + Circadian Rhythm & Identify genes that change in either an up-down or down-up pattern, \\
Full & $\sim$ Disk number + Time + Time & controlling for leaf variability \\
Reduced & $\sim$ Disk number & $\ldots$ \\
\hline
\end{tabular}

\footnotetext{
${ }^{\mathrm{z}}$ These models were subjected to the likelihood ratio test in DESeq2, represented in a full and reduced formulation.
} 
photosynthesis-associated gene unique to the 24-hpc time point. Considering genes from the union of all three models, which represent general response to cold stress, pathways associated with the molecular networks for transport electron carriers, photosynthesis antennae proteins, and the photosynthesis reaction centers (I and II) were all highly, uniformly downregulated (Fig. 3). The plant photosystem I (PSI) super complex family within the transport electron carrier pathway was almost completely downregulated, with gene precursors to 22 of 29 proteins in this pathway differentially downregulated. Similarly, within the photosynthesis antenna proteins pathway, gene precursors to all light-harvesting complex proteins except for one (10 of 11) were differentially downregulated. The photosynthesis molecular network is much larger but, broadly, 34 of 36 DEGs reported in our RNAseq dataset that were a part of this pathway were downregulated. These downregulated genes were most associated with PSII and cytochromes b6 and c6. Thus, gene precursors to proteins of both PSII and PSI were significantly
A

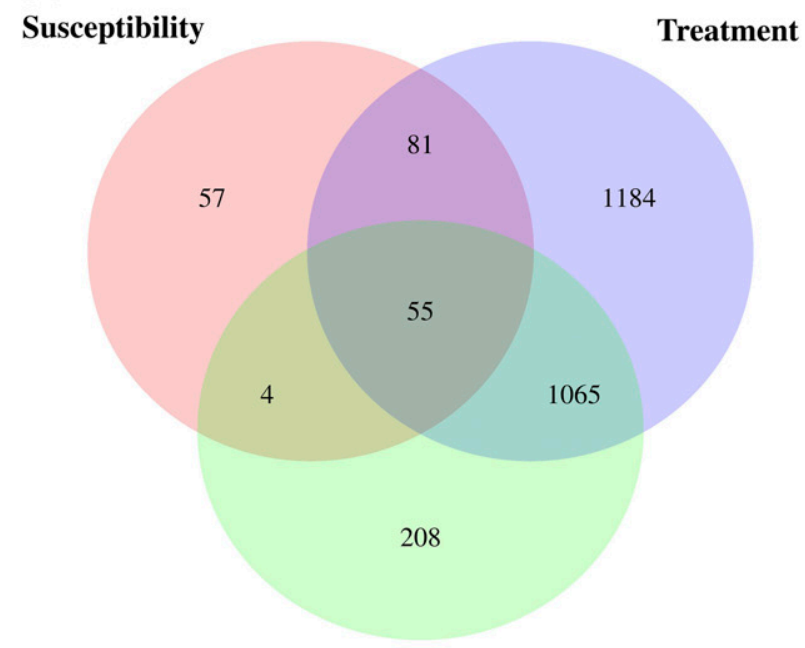

Time $^{2}$
B

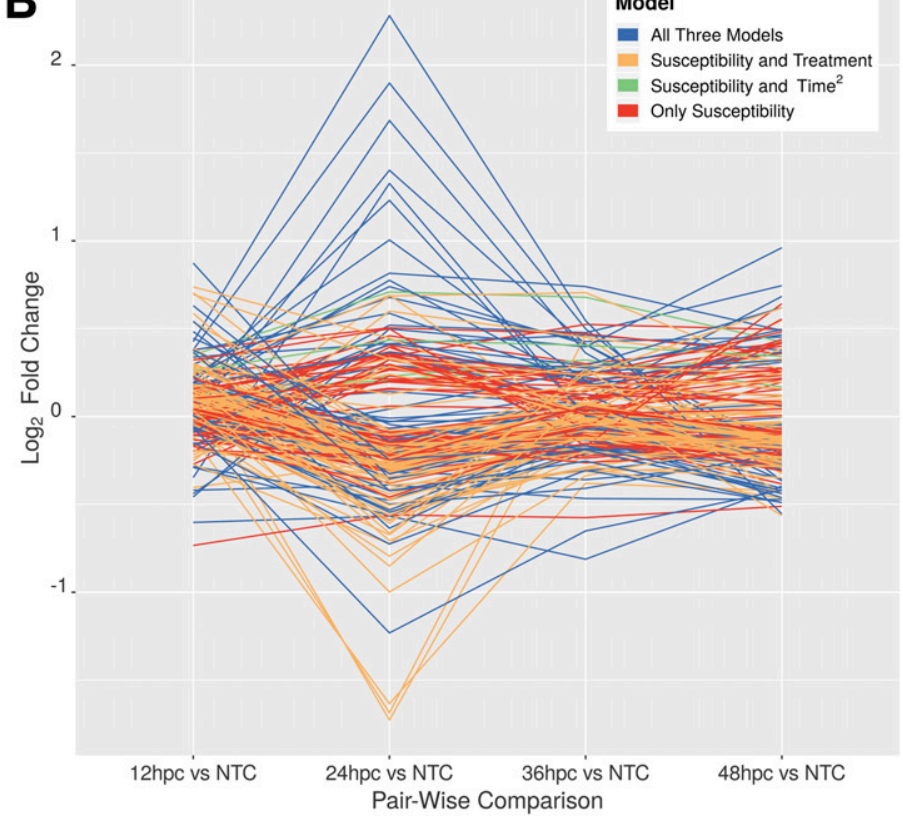

Fig. 2. Quantification of the differential gene expression (DEG) associated with the cold stress-induced disease resistance phenotype. A, Venn diagram overlaying the 2,655 DEGs identified in the likelihood ratio tests of the three different formulas used to model the transcript expression data, with each DEG partitioned based on membership in one, two, or all three model outputs. B, Relative expression profiles $\left(\log _{2}\right.$ fold change $\left.\left[\mathrm{L}_{2} \mathrm{FC}\right]\right)$ of the 197 genes identified as differentially expressed in the susceptibility model only or in the susceptibility model plus one or both of the other models. The $\mathrm{L}_{2} \mathrm{FC}$ of each gene is visualized across each of the four acute cold treatment time points $(12,24,36$, and $48 \mathrm{~h}$ post-cold [hpc]) in a pairwise comparison relative to gene expression values of the nontreated control (NTC) group.

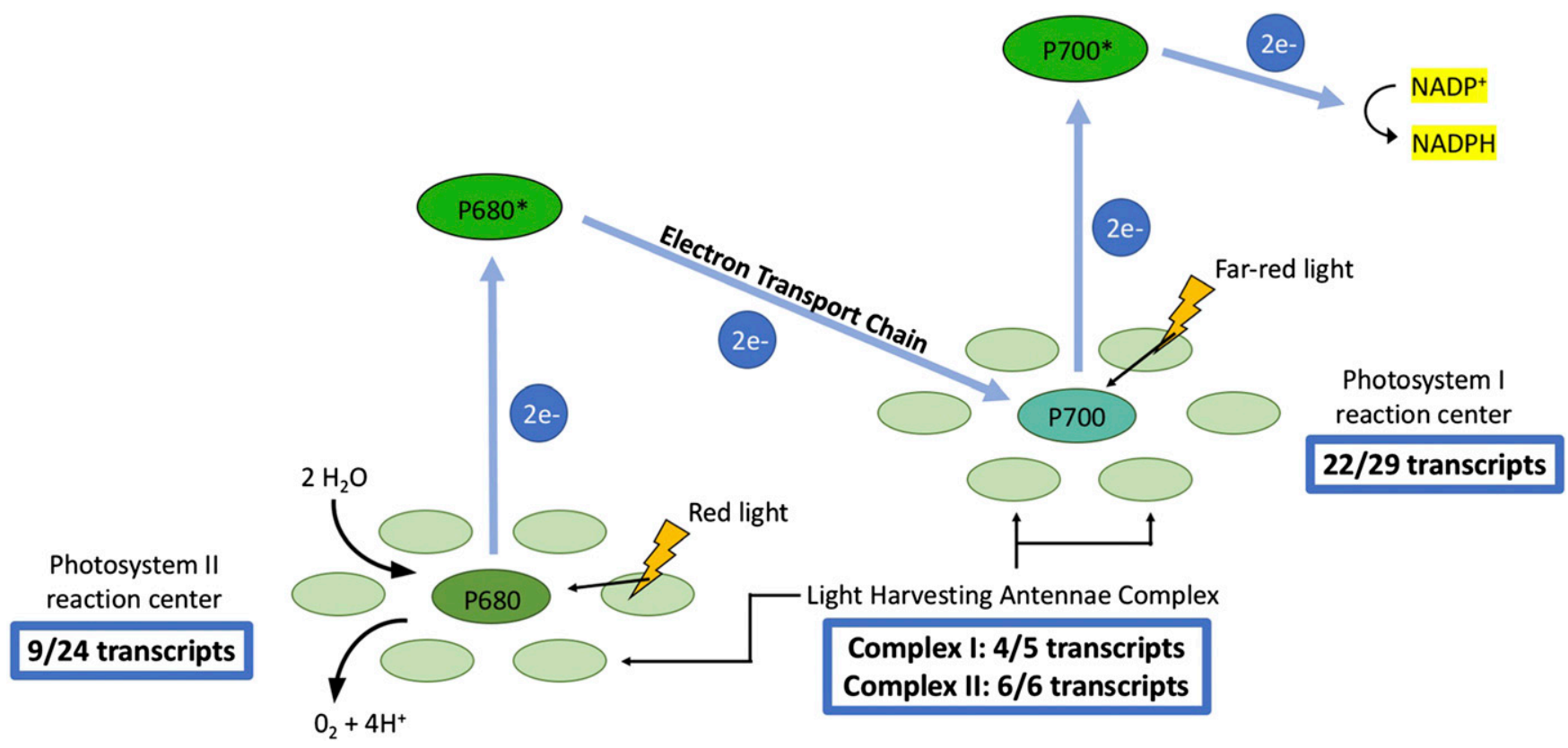

Fig. 3. The Z-scheme of photosynthesis electron transport, as described by Taiz and Zeiger (2006). Photosystem I, photosystem II, and the Light Harvesting Antennae Complex are annotated with the proportion of transcripts in each VitisNet $12 \mathrm{X}$ pathway differentially downregulated in our dataset. 
downregulated, as well as almost all gene precursors to proteins that make up the light-harvesting antennae complex.

Hypothesis 2. Cold SIDR is driven by sink-to-source transitionassociated transcriptional responses that mimic a temporary induction of an ontogenic resistance. The starch and sucrose metabolism pathway was enriched in the upregulated gene cluster 3 (Table 3). Three gene precursors to $\alpha$-amylase were upregulated, which are involved in conversion of starch to dextrin. Additionally, three gene precursors to glucan endo-1,3- $\beta$-D-glucosidase were upregulated. In the subset of XD overlapping between models 1 and 2 , there were no genes within the starch and sucrose metabolism pathway unique to the 24-hpc time point. However, there was a mosaic of up- and downregulated genes scattered throughout the starch and sucrose metabolism pathway framework, with no clear pattern.

Hypothesis 3. Cold SIDR results from modified regulation of phytohormone pathways, especially those associated with cell growth and abiotic stress responses. Gene cluster 2 indicated downregulation of gibberellic-acid-producing genes and a gibberellic acid catabolism-associated pathway. The DEGs belonging to the ABA signaling pathway were largely downregulated but were also mainly precursors to proteins that are

Table 3. VitisPathways relevant to any of the three proposed cold stress-induced disease resistance hypotheses that were also reported in gene clusters (Cls) that followed an expression pattern peaking at $24 \mathrm{~h}$ postcold, either upregulated (cluster 3) or downregulated (cluster 2)

\begin{tabular}{|c|c|c|c|c|c|}
\hline Cls & $\begin{array}{l}\text { Mean } \\
\mathbf{L}_{2} \mathbf{F C}^{\mathbf{y}}\end{array}$ & VitisPathway & $\begin{array}{c}P \\
\text { value }^{z}\end{array}$ & Specific genes & Gene functions \\
\hline 2 & 0.983 & $\begin{array}{l}\text { Photosynthesis antenna } \\
\text { proteins }\end{array}$ & 0 & $\begin{array}{l}\text { Vitvil0g00740, Vitvi10g00372, } \\
\text { Vitvi10g00378, Vitvi19g00298 }\end{array}$ & Chlorophyll a-b binding protein \\
\hline 2 & 0.983 & Transport electron carriers & 0 & $\begin{array}{l}\text { Vitvi19g00298, Vitvi10g00372, } \\
\text { Vitvi10g00378, Vitvi10g00740 }\end{array}$ & Chlorophyll a-b binding protein \\
\hline 2 & 0.983 & Porters category 30-64 & 0.002 & $\begin{array}{l}\text { Vitvi13g00242, Vitvi14g01624, } \\
\quad \text { Vitvi18g00365 }\end{array}$ & Ion transport, cell membrane component, transporter \\
\hline 3 & 0.758 & Circadian rhythm & 0 & $\begin{array}{l}\text { Vitvi01g00499, Vitvi16g01340, } \\
\text { Vitvi13g01892 }\end{array}$ & $\begin{array}{l}\text { Response to abiotic stimulus, cell signal transduction, } \\
\text { circadian rhythm }\end{array}$ \\
\hline 3 & 0.758 & $\begin{array}{l}\text { Glyoxylate and } \\
\text { dicarboxylate metabolism }\end{array}$ & 0.01 & Vitvi12g00505, Vitvi09g01499 & $\begin{array}{l}\text { Citric acid cycle associated, glyoxylate cycle activated when } \\
\text { complex carbons like glucose are unavailable }\end{array}$ \\
\hline 3 & 0.758 & Cytokinin signaling & 0.014 & Vitvi15g01021, Vitvi16g01340 & $\begin{array}{l}\text { Transcription regulator, signal transduction, response to } \\
\text { abiotic stress }\end{array}$ \\
\hline 3 & 0.758 & PseudoARR-B & 0.017 & Vitvil6g01340 & Important in plant circadian oscillation \\
\hline 3 & 0.758 & Methane metabolism & 0.028 & Vitvi12g02237, Vitvi08g00821 & - \\
\hline 3 & 0.758 & $\begin{array}{l}\text { Starch and sucrose } \\
\text { metabolism }\end{array}$ & 0.038 & $\begin{array}{l}\text { Vitvi10g00085, Vitvi12g00686, } \\
\text { Vitvi02g00605 }\end{array}$ & $\begin{array}{l}\text { Breakdown of sucrose for generation of usable sugar } \\
\text { by the pathogen }\end{array}$ \\
\hline 3 & 0.758 & Thiamine metabolism & 0.039 & Vitvilog00027 & $\begin{array}{l}\text { Plays a vital role in metabolism of glucose in } \\
\text { glycolysis to generate ATP }\end{array}$ \\
\hline 3 & 0.758 & HSF & 0.042 & Vitvi01g00511 & Heat stress transcription factors \\
\hline 3 & 0.758 & AP2_EREBP & 0.045 & Vitvi13g00116, Vitvi15g01021 & $\begin{array}{l}\text { AP2/EREBP transcription factors have been implicated in hormone, } \\
\text { sugar and redox signaling in context of abiotic stresses. }\end{array}$ \\
\hline
\end{tabular}

${ }^{y}$ Mean $\log _{2}$ fold change $\left(\mathrm{L}_{2} \mathrm{FC}\right)$ of the differentially expressed genes within the given pathway at $24 \mathrm{~h}$ postcold time point as compared with the nontreated control group.

${ }^{\mathrm{z}}$ Corrected $P$ value calculated as the tallied number of permuted $P$ values at least as significant for a permutated gene list as for the original gene list, with 1,000 permutations used.

Table 4. Differentially expressed genes at $24 \mathrm{~h}$ post-cold (hpc) treatment, initially identified by pathway enrichment analysis and having a function relevant to powdery mildew resistance biology

\begin{tabular}{|c|c|c|c|}
\hline Gene cluster & $\mathrm{L}_{2} \mathrm{FC}$ at $24 \mathrm{hpc}^{\mathrm{y}}$ & Vitis gene name (V3) & Function $^{z}$ \\
\hline 2 & -0.9602 & Vitvil1g01295 & Pathogenesis-related protein 1 precursor (PRP 1) \\
\hline 2 & -0.9024 & Vitvilog00378 & LHCB3 (light-harvesting chlorophyll binding protein 3) \\
\hline 2 & -0.6784 & Vitvil6g00890 & $\begin{array}{l}\text { Gibberellin } 3 \text { - } \beta \text {-dioxygenase, involved in production of bioactive } \\
\text { gibberellic acid }\end{array}$ \\
\hline 2 & -0.9658 & Vitvi13g00351 & Wall-associated receptor-like kinase $\left(\mathrm{Ca}^{2+}\right.$ mediated $)$ \\
\hline 2 & -1.1347 & Vitvi15g00885 & Starch synthase \\
\hline 2 & -0.6115 & Vitvi19g00298 & LHCII type III, chloroplast precursor \\
\hline 3 & 2.2816 & Vitvilog01384 & DNAJ heat shock N-terminal domain-containing protein \\
\hline 3 & 0.9772 & Vitvi13g00116 & $\begin{array}{l}\text { Dehydration-responsive element-binding protein } 2 \mathrm{C} \text { (Associated } \\
\text { with abscisic acid mediated signaling) }\end{array}$ \\
\hline 3 & 0.6658 & Vitvi01g00511 & Heat stress transcription factor A-8 \\
\hline 3 & 1.3404 & Vitvi18g00789 & $\begin{array}{l}\text { Unknown protein (AT5G42900 homolog: COR27/COLD } \\
\text { REGULATED GENE 27) }\end{array}$ \\
\hline 3 & 1.0149 & Vitvi06g01016 & ABA signaling pathway \\
\hline 3 & 1.0850 & Vitvi09g01181 & NBS-LRR superfamily \\
\hline 3 & 0.6551 & Vitvi12g02756 & NBS-LRR superfamily \\
\hline 3 & 0.5717 & Vitvi12g02237 & Peroxidase \\
\hline 3 & 0.5797 & Vitvi02g00468 & HMG regulation of transcription \\
\hline 3 & 0.2904 & Vitvi17g00131 & Calcium sensors and signaling \\
\hline 3 & 0.4467 & Vitvi13g00172 & Expansin signaling hormone \\
\hline 11 & -0.5449 & Vitvi07g01217 & MLO1 \\
\hline 13 & 1.5988 & Vitvi05g01911 & Inhibitor of trypsin and Hageman factor (CMTI-V) \\
\hline
\end{tabular}

${ }^{y}$ Mean $\log _{2}$ fold change $\left(\mathrm{L}_{2} \mathrm{FC}\right)$ of the 24-hpc group relative to the gene expression of the nontreated control group.

${ }^{\mathrm{z}} \mathrm{ABA}=$ abscisic acid and NBS-LRR = nucleotide-binding site leucine-rich repeat. 
negative regulators of $\mathrm{ABA}$ biosynthesis, including $A B I 1$, $A B I 2$, and $A H G 3$. Although ABA biosynthesis inhibition was largely downregulated (which would net result in upregulation), our dataset did not return a single DEG precursor belonging to the ABA biosynthesis pathway. WRKY transcription factors, which are regulatory proteins associated with responses to abiotic and biotic stressors, were largely upregulated. Six of eight differentially expressed WRKY gene precursors were upregulated; however, none were unique to the 24-hpc resistant time point in model 1. Eight $C O R$ homologs were downregulated in gene cluster 2 and $18 C O R$ homologs were upregulated in gene cluster 3, indicating that the downstream effects of the ICE-CBF pathway may have still been active at this time point (Supplementary Table S2). Of the eight COR homologs downregulated in gene cluster 2, two genes were exclusive to the 24-hpc time point - a Dynein light chain 1 (DLC1) LC8type gene (Vitvi19g00302) and a gene precursor to methionine sulfoxide reductase (Vitvi05g00390). Of the 18 COR homologs upregulated in gene cluster 3 , three genes were exclusive to the 24-hpc time point-expansin EXPA8 (Vitvi13g00172), an F-box protein precursor (Vitvi09g00793), and a precursor to a protein of unknown function (Vitvi06g00579).

Hypothesis discovery. There was also a collection of strong candidate genes that did not directly associate with any of the three alternative hypotheses (Table 5). Within the group of transcripts that were differentially regulated for both a cold response (model 2) and the resistance phenotype (model 1), two nodulin 1A genes (Vitvi03g01540 and Vitvi03g01543) and a gene precursor to nodulin, MtN21 (Vitvi01g00815), were strongly downregulated. A gene precursor to $M L O 1$ (Vitvi07g01217) was differentially downregulated, as was heat shock transcription factor $A 6 B$ (Vitvi07g00078) specifically at $24 \mathrm{hpc}$. Upregulated gene precursors of note include two gene precursors to proteins involved in protein folding - Chaperonin GroEL (Vitvi01g01339) and a DNAJ heat shock N-terminal domain-containing protein (Vitvilog01384), which was the most differentially regulated transcript in the entire dataset in either direction.

\section{DISCUSSION}

When $V$. vinifera 'Chardonnay' leaves were exposed to periods of acute cold at varied time points prior to inoculation with $E$. necator, a transient host resistance phenotype was observed. In agreement with prior work, grape leaf response to cold also induced a temporary downstream resistance response to E. necator. We observed a significant reduction in the percentage of germinated conidia that were able to develop beyond an initial appressorium but the spores that did grow past this stage also generally went on to successfully develop into an established mildew colony. This indicated that the cold SIDR host resistance is negatively affecting $E$. necator during initial establishment of the haustorial interface, before spores have produced secondary hyphae and established a lasting hostpathogen interaction.

A previous review of acute cold SIDR posed three general hypotheses as explanations for how a host response to cold may be also temporarily inducing a host resistance phenotype against the obligately biotrophic pathogen E. necator (Moyer et al. 2016). Based on the gene expression data generated from our current study, three questions emerge. (i) Where do the three hypotheses now stand? (ii) What were the overall trends observed and how do they affect the big picture explanation of what may be driving the cold SIDR phenomenon at the molecular level? (iii) Are there additional pathways of interest that don't necessarily fit within the three original hypotheses?

Hypothesis one, suggesting that a less photosynthetically active host would temporarily create imbalances in host ability to harvest light energy versus use this energy for metabolism, is largely supported in our expression data through downregulated photosynthesis-associated pathways, including the transport electron carrier network, photosynthesis antennae protein network, and larger photosynthesis network itself. However, the vast majority of these downregulated genes from our dataset were not exclusively downregulated at the 24-hpc time point, indicating that this was more of a general response to acute cold. Although not unique to the 24 -hpc resistance time point, a sweeping downregulation of photosynthetic activity within the antennae protein complex and PSI reaction center cannot be ignored as a possible factor in the cold SIDR response. The effects of a stunted photosynthetic rate could be short lived, and its impact could peak at a specific time point downstream, such as $24 \mathrm{~h}$ following the cold event.

Hypothesis two proposed that a temporary period of ontogenic-like resistance is induced, where the grape host moves from a net carbon consumer to a carbon source. Starch and sucrose metabolism pathways were generally indicated to be moving in an unchanged or upregulated direction, as were the pathways associated with ATP production, which would generally indicate that the leaf tissue is still consuming high

Table 5. Vitis vinifera transcripts that did not fall specifically within any of the three cold stress-induced disease resistance (SIDR) alternative hypotheses but were differentially regulated genes reported in the percentage susceptibility model or the union of that model with one or both of the other models and had potentially relevant gene functions associated with cold SIDR

\begin{tabular}{|c|c|c|c|}
\hline Vitis gene name (V3) & $\mathrm{L}_{2} \mathrm{FC}$ at $24 \mathrm{hpc}^{\mathrm{y}}$ & Functional annotation & Best Arabidopsis gene match ${ }^{\mathrm{z}}$ \\
\hline Vitvi03g01540 & -1.7270 & Nodulin 1A, senescence-associated & AT3G19000 \\
\hline Vitvi07g00814 & -1.6857 & Tetratricopeptide repeat domain male sterility MS5 & AT5G48850 \\
\hline Vitvi03g01543 & -1.6336 & Nodulin $1 \mathrm{~A}$, senescence-associated & AT3G19000 \\
\hline Vitvi19g00302 & -1.2313 & Dynein light chain LC8-type & $A T 4 G 27360$ \\
\hline Vitvil6g01310 & -0.9984 & No hit & NA \\
\hline Vitvi18g01510 & -0.8507 & Seed maturation protein PM31 & AT3G46230 \\
\hline Vitvi01g00815 & -0.7946 & Nodulin MtN21 family & $A T 1 G 70260$ \\
\hline Vitvi18g00341 & -0.7252 & Glycine hydroxymethyltransferase & $A T 1 G 36370$ \\
\hline Vitvi07g00078 & -0.5607 & Heat shock transcription factor A6B & AT3G22830 \\
\hline Vitvi07g01217 & -0.5449 & MLO1 & AT4G02600 \\
\hline Vitvi01g01339 & 0.7398 & Chaperonin GroEL & $A T 1 G 26230$ \\
\hline Vitvi09g00793 & 1.0053 & F-box protein (FBL14) & $A T 1 G 80570$ \\
\hline Vitvi01g00156 & 1.6849 & Pentatricopeptide (PPR) repeat & NA \\
\hline Vitvilog01384 & 2.2816 & DNAJ heat shock $\mathrm{N}$-terminal domain-containing protein & AT5G23240 \\
\hline
\end{tabular}

\footnotetext{
${ }^{x}$ All of these genes are reported to be uniquely regulated at the $24 \mathrm{~h}$ post-cold (hpc) time point of greatest interest.

${ }^{y}$ Mean $\log _{2}$ fold change $\left(\mathrm{L}_{2} \mathrm{FC}\right)$ of the 24 -hpc group relative to the gene expression of the nontreated control group.

${ }^{\mathrm{z}} \mathrm{NA}=$ not applicable.
} 
amounts of sucrose. We did observe some upregulation of ROSassociated genes but the other pathways associated with hypothesis two appear largely unsupported. However, a host that is downregulated in its photosynthetic activity but still active from the standpoint of carbon consumption would further exacerbate any energy imbalance, as previously mentioned as part of hypothesis one. In this way, although hypothesis two alone is largely unsupported, the gene expression patterns associated with hypotheses one and two could come together to further strengthen hypothesis one and provide a general explanation for the transcriptional changes driving the cold SIDR phenomenon.

Hypothesis three suggests an acute cold SIDR phenotype achieved through regulatory changes in plant hormone signaling, especially those associated with reduced cell growth and elongation or induction of abiotic stress response pathways. There was evidence of upregulation of plant hormone signaling pathways through expression of calcium signaling cascade genes, which are thought to be responsible for downstream induction of ICE genes and which are likely involved in inducing the changes associated with many of the 26 COR genes that were either down- or upregulated at $24 \mathrm{hpc}$. However, as in the case of the photosynthesis-associated pathways, many of these COR genes were not unique to the 24 -hpc time point alone. There were two downregulated (gene cluster 2 ) and three upregulated (gene cluster 3) COR genes that were specific to our resistance time point and could be targets for future work. Some of our most significant $\mathrm{L}_{2} \mathrm{FC}$ values in gene cluster 3 were associated with dehydration and heat stress response genes, which have been reported to have shared responses with disease resistance and be very tightly linked to $C B F$ coldresponse genes $A t C B F 1, A t C B F 2$, and $A t C B F 3$ (Novillo et al. 2007). Ultimately, the gene expression data associated with hypothesis three provides a handful of candidate $C O R$ genes that may be contributing to the quantitative nature of the cold SIDR response. Further analysis of these genes is necessary to truly elucidate their role, if any, in the biological system.

Finally, considering potential transcriptional changes to single genes or small groups of related genes, there was a collection that did not fit within any three of the hypotheses yet included some of our most highly regulated transcripts that were specifically associated with the 24-hpc resistance time point (Table 5). The most relevant to note were genes that were strongly downregulated and involved in transport of nutrients and amino acids throughout the plant. Specifically, two nodulin $1 A$ gene precursors, a gene precursor to nodulin $M t N 21$, and a gene precursor to DLC1 motor protein were four of the eight most downregulated genes. A recent review (Denancé et al. 2014) highlighted an emerging importance of nodulin-like proteins as transporters of nutrients, solutes, amino acids, and hormones in nonnodulating plant species, including $V$. vinifera. MtN21 proteins have been reported to be involved in amino acid transport (Ladwig et al. 2012), while the DLCl complex is more heavily studied in mammalian systems as being involved in intracellular trafficking of vesicles and organelles along microtubules (Lo et al. 2001; Williams et al. 2007). In plant systems, the $D L C 1$ complex was recently surveyed for conservation across 15 plant species, revealing that the dynein genes of $V$. vinifera and A. thaliana were grouped together phylogenetically (Cao et al. 2017). In this same study, Arabidopsis DLC genes were shown to be responsive to abiotic stressors such as cold, heat, and drought. The A. thaliana homolog to the $V$. vinifera DLC1 gene (Vitvi19g00302) that was highly downregulated in our study was reported to be cold responsive but in a mildly upregulated direction. Though we observed little evidence of decreased metabolic activity and metabolism of sucrose sugars, a temporary decrease in plant transport of nutrients could exacerbate suboptimal sinks in host tissue that could result in incompatible haustorial nutrient exchange for E. necator.

Another expression trend outside of the initial hypotheses that was uniquely associated with the 24-hpc time point was a $0.545 \mathrm{~L}_{2} \mathrm{FC}$ downregulation of VvMLO5, as annotated by Winterhagen et al. (2008). Some members of the $M L O$ gene family have been extensively characterized as powdery mildew susceptibility genes (Appiano et al. 2015; Guo et al. 2018; Kusch and Panstruga 2017; Zhu et al. 2018) and, similar to cold SIDR, reduced $M L O$ expression reduces penetration success percentage. However, previous studies have not identified this ortholog as potentially involved in powdery mildew susceptibility (Feechan et al. 2008; Winterhagen et al. 2008).

A final trend outside of the initial hypotheses was associated with upregulated transcripts coding for chaperone proteins that regulate protein folding, one of which was a precursor to a DNAJ heat shock protein and the other a precursor to a chaperonin GroEL protein. Although lower temperatures generally increase the stability of proteins, favoring the native state, chaperonins are thought to have some activity in further stabilization of "cold labile" proteins (Guy et al. 1996). It is possible that the increased chaperonin activity is enhancing host protein stability in the epidermis and, therefore, decreasing penetration success.

Cold SIDR is an induced resistance response within powdery mildew pathosystems that has been observed in diverse plant species, including grapevine and hops (Moyer et al. 2010; Weldon et al. 2017). This provides opportunities for comparative expression analysis between hosts to uncover the shared genes and pathways underlying cold SIDR, and for utilization of diverse genetic tools for functional validation of the traits for which we now have specific gene candidates. When successfully understood and manipulated, cold SIDR then also has the potential for broad impact in managing powdery mildews of diverse crops or other obligately biotrophic pathogen groups that intimately rely on host equilibrium for successful growth.

The vast majority of commercially grown $V$. vinifera grapes receive regular applications of pesticides and mechanical intervention at multiple phenological stages throughout the season (Wilcox et al. 2015). It is reasonable to consider application of acute, mechanical cold treatments as an additional disease management tool worth further exploration. Moreover, the predictable nature of the response would allow environmentally driven advisory models to more accurately describe epidemic progress, because acute cold events could partially or completely reverse the impact of longer periods of environmental favorability. Indeed, the unexpected early-season stalling of epidemics of grapevine powdery mildew was circumstantially linked to acute cold events by Moyer et al. (2010). Our work provides new evidence linking preinfection cold events, genetic changes in response to acute cold, consequent enhanced resistance of the host, and suppression of pathogen development.

\section{MATERIALS AND METHODS}

\section{E. necator isolate maintenance.}

E. necator isolate NY90 (Barba et al. 2015) was maintained in culture on detached $V$. vinifera 'Chardonnay' leaves from either the second or third node of greenhouse-grown potted vines with a 16 -h daylength at $24^{\circ} \mathrm{C}, 8-\mathrm{h}$ night at $21^{\circ} \mathrm{C}$, and a high-pressure sodium bulb lighting source (600 W, VIVOSUN). The leaves were removed at the base of the petiole and surface sterilized through a 1-min rinse in $1 \%$ sodium hypochlorite aqueous solution, followed by two successive 1-min rinses in distilled water. Upon surface sterilization, each leaf was placed into a double Petri dish, which is constructed by melting a hole from the base of the top dish through the lid of the bottom dish. 
This fuses the dishes together and provides a hole for the leaf petiole to pass from the upper dish that houses the leaf to the lower that contains distilled water. Using a fine-tipped paint brush, E. necator isolate NY90 was inoculated onto the adaxial leaf surface. Isolates were maintained in growth chambers (Panasonic Versatile Environment Test Chamber, MLR-352H) at $23^{\circ} \mathrm{C}$ with a cycle of $16 \mathrm{~h}$ of light and $8 \mathrm{~h}$ of darkness, a light intensity range of 200 to $500 \mu \mathrm{mol} / \mathrm{m}^{2} / \mathrm{s}$, and $50 \%$ relative humidity. Isolates were transferred every 10 to 12 days to maintain actively growing, healthy colonies of E. necator.

\section{Cold SIDR and ontogenic resistance.}

The effects of grape leaf age on the cold SIDR phenotype were investigated to test for additive effects of ontogenic resistance and cold SIDR. Leaf age was defined by the position of a leaf from the apex of a shoot, with leaf position one being the most recently unfolded leaf at the apex of a shoot. Leaf one and three progressively older leaves were collected from greenhouse-grown potted vines of Chardonnay and surface sterilized as described above prior to plating on $1 \%$ (wt/vol) aqueous agar (Fisher Chemical A360-500) Petri dishes. Control samples were maintained at room temperature $\left(22^{\circ} \mathrm{C}\right)$. All acute cold events described below were simulated in a lowtemperature incubator (Precision Low-Temperature Incubator, 815 series) growth chamber maintained at $4^{\circ} \mathrm{C}$ for $4 \mathrm{~h}$. This experiment consisted of three biological replicates (separately potted vines) with two shoots per vine providing paired treatments (control shoot and cold-treated shoot) and was repeated twice.

Inoculation with $E$. necator isolate NY90 took place $24 \mathrm{~h}$ after the completion of the cold treatment by dusting conidia from Chardonnay inoculum leaves to experimental leaves using a dry paint brush. All leaves were subsequently maintained at room temperature for $48 \mathrm{~h}$ to allow the conidia to develop prior to clearing, Coomassie Blue staining, mounting in $25 \%$ glycerol, and assessment of fungal penetration success percentage at $\times 100$ magnification (Zeiss Axiophot EL-Einsatz compound light microscope) were performed as previously described (Moyer et al. 2010). One hundred conidia per leaf were observed for calculation of penetration success percentage, defined as the percentage of germinated conidia forming at least one secondary hypha (Barba et al. 2015). Analysis of variance (ANOVA) was performed to test for statistically significant differences in penetration success percentages among treatments and leaf positions (SAS Institute Inc. 2019).

\section{Detached grape leaves versus leaf disks.}

Given that host stresses can induce resistance to E. necator, this experiment was conducted to determine whether physical damage from cutting leaf disks transiently affects penetration resistance relative to whole detached leaves. Leaves were collected from greenhouse-grown potted vines of $V$. vinifera 'Chardonnay' and surface sterilized as described above prior to plating on $1 \%$ agar Petri dishes (90 $\mathrm{mm}$ in diameter). Using a 1-cm-diameter cork borer, leaf disks were cut from surfacesterilized leaves, then placed on $1 \%$ agar Petri dishes. All samples were maintained at room temperature $\left(22^{\circ} \mathrm{C}\right)$. The experiment consisted of three biological replicates (separately potted vines), with two shoots per vine providing paired treatments (whole leaf and disk), and was repeated twice.

Inoculation with E. necator isolate NY90 took place at three time points after cutting of disks $(0,24$, and $48 \mathrm{~h})$ to assess whether the time since the leaf disks were cut had any effect on infection. All leaves were subsequently maintained at room temperature for $48 \mathrm{~h}$ after inoculation for staining and calculation of penetration success percentage, as described above. ANOVA was performed to test for statistically significant differences in penetration success percentage among whole leaves and leaf disks at all three inoculation time points (SAS Institute Inc. 2019).

\section{Grape cold SIDR time course phenotype experiment.}

Experimental design. The goal was to confirm the range of time points following an acute cold event in which a significant reduction in host susceptibility to $E$. necator infection is observed, and then pair this with $3^{\prime}$ RNAseq at all time points to investigate the unique transcriptional changes observed at the time points of greatest resistance. To accomplish this, acute cold events were simulated as described above at $48,36,24$, or $12 \mathrm{~h}$ prior to simultaneous inoculation of all treatments with E. necator isolate NY90 (Fig. 4). The NTC did not experience an acute cold event prior to inoculation.

The experiments were executed as follows. A single $1 \%$ agar Petri dish was assigned to each of five treatment groups: NTC or $48,36,24$, or $12 \mathrm{hpc}$. The bottom of each Petri dish was labeled with a $4-$ by $-41-\mathrm{cm}^{2}$ grid to track leaf disks. Fifteen susceptible Chardonnay leaves from the third node were collected and surface sterilized as described above. Using a 1-cmdiameter cork borer, five leaf disks were cut from each leaf at varied, nonspecific locations across the entire leaf area and one disk was randomly assigned to each of the five treatment group Petri dishes. This resulted in 15 leaf disks per treatment originating from the same 15 source leaves. The source leaf was tracked for each disk, which enabled controlling for phenotypic or expression variation observed between leaves. The lamina length of representative third node and fully expanded leaves of potted $V$. vinifera 'Chardonnay' shoots were recorded to provide a general estimate of sink-to-source transition status within the third node leaves used for phenotyping the cold SIDR response.

After leaf disks were cut and placed into the Petri dishes, all samples were stored overnight in the same growth chamber and conditions as for isolate maintenance, as well as at all times during the experiment except during cold treatment. The following morning at 7 A.M., starting with the 48-hpc treatment group, acute cold events were executed every $12 \mathrm{~h}$ leading up to the time of inoculation. Acute cold events for the 48- and 24-hpc treatments occurred from 7 A.M., until 11 A.M., (48 hpc on day 1 and $24 \mathrm{hpc}$ on day 2). Acute cold events for the 36- and 12-hpc treatments occurred from 7 P.M. until 11 P.M. ( $36 \mathrm{hpc}$ on day 1 and $12 \mathrm{hpc}$ on day 2). An overhead white-light LED inside the low-temperature incubator for the duration of all acute cold events ensured that the photoperiod was not disrupted even during treatment $\left(23^{\circ} \mathrm{C}, 16 \mathrm{~h}\right.$ of light from A.M. to 11 P.M., and 50\% relative humidity).

To collect samples destined for $3^{\prime}$ RNAseq, $12 \mathrm{~h}$ after the final cold treatment group ( $12 \mathrm{hpc}$ ), leaf disks 11 to 15 from each treatment group were transferred to individual 2-ml microcentrifuge tubes (Eppendorf safe-lock tubes, $2.0 \mathrm{ml}$; catalog number 022363344) that contained two stainless-steel beads (SPEX sample prep item number 2150) and approximately $300.1-\mathrm{mm}$ glass beads (Scientific Industries, Inc., part number SI-BG01). The samples were then flash frozen in liquid nitrogen and stored at $-80^{\circ} \mathrm{C}$. At the same time, the remaining 10 leaf disks (disks 1 to 10) from each treatment group were transferred to a glass Pyrex tray (Pyrex Borosilicate tray, model number 291B000/5016) containing $700 \mathrm{ml}$ of $1 \%$ agar. A $1-\mathrm{cm}^{2}$ grid pattern was taped onto the underside of the tray, and leaf disks from all treatments were arranged in a spatially balanced replicate block pattern within the grid. All leaf disks were inoculated using a fine-tipped paint brush for transfer of conidia from 12-day-old E. necator NY90 colonies. An inverted glass Pyrex tray was used as a lid, and the tray was kept in the growth chamber for $48 \mathrm{~h}$ in the same conditions for pathogen growth. After $48 \mathrm{~h}$, samples were placed in clearing solution to stop colony growth and begin sample staining. 
Staining protocol. Using 24-well trays, leaf disks were placed in a clearing solution of 3:1 ethanol (Koptec 190-proof pure ethanol) and glacial acetic acid (EMD Millipore Corporation, CAS number 64-19-7) for $2 \mathrm{~h}$. The clearing solution was discarded and replaced for an additional $4 \mathrm{~h}$. The clearing solution was discarded again, and samples were washed with $30 \%$ ethanol (Koptec 190-proof pure ethanol) for $15 \mathrm{~min}$, then submerged in a $0.5 \%$ (wt/vol) chlorazol black (Sigma Aldrich C1144-5G) aqueous staining solution for $12 \mathrm{~h}$ overnight. After $12 \mathrm{~h}$, samples were washed with distilled water and mounted on glass microscope slides in $25 \%$ (vol/vol) glycerol (Alfa Aesar catalog number A16205) under a cover slip. This method is nearly identical to the Coomassie Blue method cited above, except that chlorazol black E provides higher-contrast staining and allows for overnight staining of leaf tissue.

Phenotyping data collection. Stained and mounted leaf disk samples were phenotyped microscopically at $\times 100$ magnification (Zeiss Axiophot EL-Einsatz compound light microscope). Each leaf disk was phenotyped by categorizing the development of 100 arbitrarily selected germinated E. necator conidia as having developed (i) an appressorium only $=A$ in the following equations, (ii) an appressorium plus a single hypha $=S$, or (iii) an appressorium plus branching hyphae $=B$. These counts were then used to calculate a penetration success percentage and a colony success percentage, as previously described (Barba et al. 2015). Briefly, penetration success was calculated as $\operatorname{PenS}=(S+B) / T$, where $\mathrm{T}=$ total number of germinated conidia counted $(A+S+B)$. Colony formation success was calculated as $C=B /(S+B)$. Penetration success and colony formation success were analyzed separately for evidence of statistical significance. Both responses were represented in generalized linear models ("lmer" package in R) (Bates et al. 2015), in which treatment was a fixed effect and leaf number was a random effect. The "emmeans" function in $\mathrm{R}$
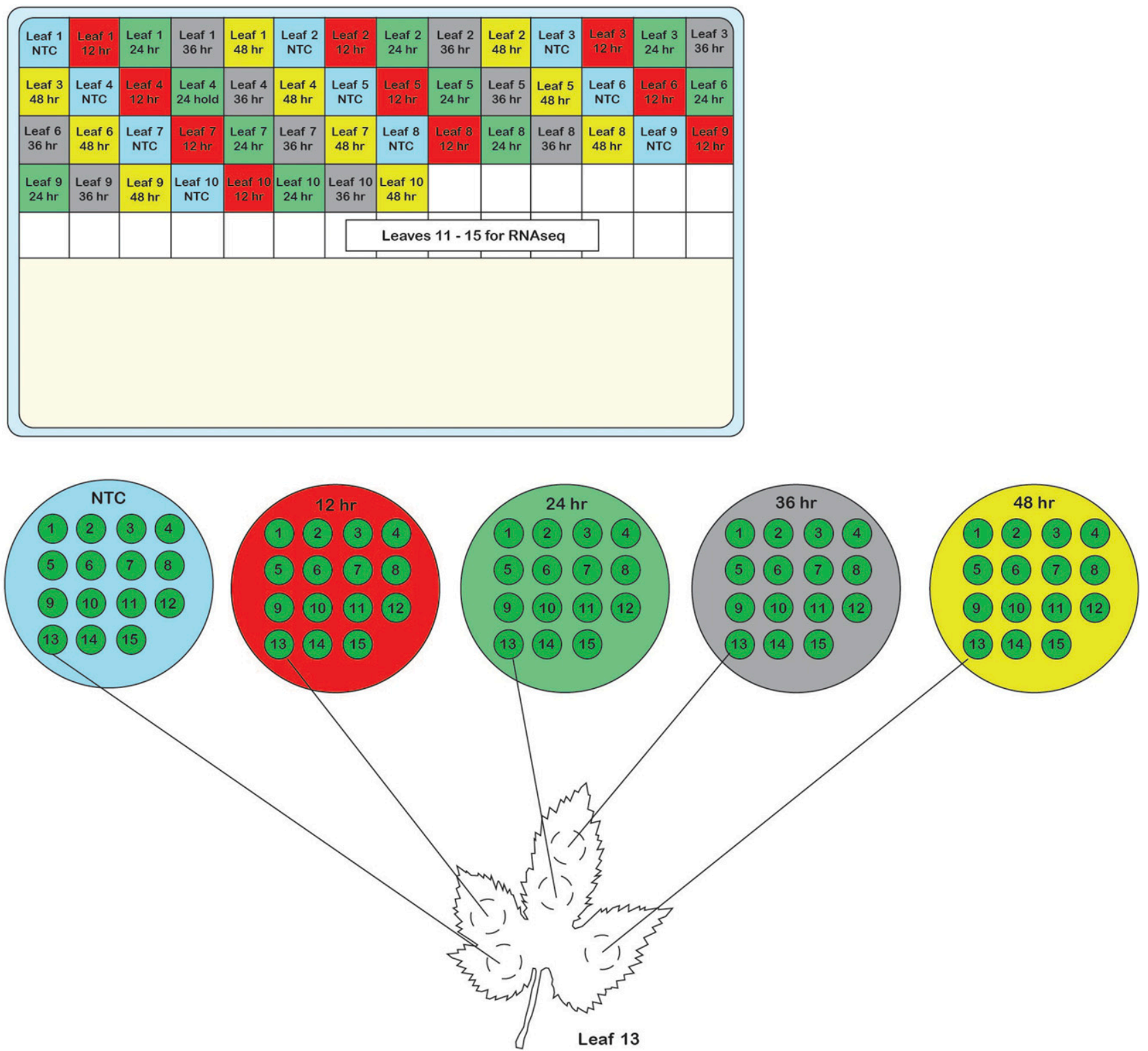

Fig. 4. Experimental design for cold-stress-induced disease resistance time course phenotyping experiment. Bottom, Leaf disks were first placed into Petri dishes so that the 15 disks of a given treatment could be cold treated together. Each of 15 leaves collected contributed one disk to each treatment, with specific disks from each leaf randomly assigned to one of the five treatment groups. NTC $=$ nontreated control. Top, Leaf disks 1 to 10 of each treatment were then moved to a borosilicate glass tray, where all disks could be inoculated together in a common environment. Leaf disks 11 to 15 were collected for $3^{\prime}$ RNA sequencing. 
(Lenth 2018) was used to perform a least-squares means pairwise comparison test of all treatment groups. A $P$ value $\leq 0.05$ indicated that two given treatment groups were significantly different.

Construction of cDNA library and 3'RNA-Illumina sequencing. Five leaf disks (numbers 11 to 15) from each treatment group were sampled for RNA extraction. Leaf tissue was ground using a Geno/Grinder (SPEX SamplePrep 2000 Geno/Grinder) with three cycles of $30 \mathrm{~s}$ at $300 \mathrm{strikes} / \mathrm{min}$. Tubes were refrozen in liquid nitrogen between each cycle. Total RNA was then extracted from all ground samples using a Spectrum Plant Total RNA Kit (Sigma Aldrich, catalog number STRN250-1KT). Total RNA samples were then quantified for quality control and normalization of samples to a minimum concentration of $100 \mathrm{ng} / \mu \mathrm{l}$ (Qubit 2.0 Fluorometer; Thermo Fisher Scientific), and aliquoted into a 96well plate for cDNA library preparation. The plate was submitted to the Cornell Biotechnology Resource Center for QC analysis (Agilent TapeStation 4200), 3' RNAseq library preparation (TruSeq RNA Library Prep Kit v2; Illumina), cDNA quality control (Agilent Fragment Analyzer; Agilent Technologies), library normalization and pooling, and Illumina sequencing using the Illumina NextSeq500 with 75-bp reads (one lane combining all 75 dual-indexed samples $=5$ replicates/treatment $\times 5$ treatments $\times 3$ experiments) according to the manufacturer's instructions (Illumina).

\section{3' RNAseq analysis.}

Preprocessing and quality analysis. Initial raw read quality was evaluated using FastQC (Babraham Bioinformatics 2012). Several tools from the Fastx-Toolkit were used for preprocessing of the sequence reads (Gordon and J. Hannon 2010). The first 13 bases were removed from the $5^{\prime}$ end of the sequence read using Fastx Trimmer due to possible sequencing errors from random priming. Fastx Quality Trimmer was used to remove low-quality bases with Phred scores $<20$ from the $3^{\prime}$ end of each read. Then, reads shorter than 38 bases were removed from the analysis. Fastx Quality Filter was used to remove sequences reads with a low overall quality based on two criteria: (i) $<80 \%$ of the bases in the read above a Phred quality score of 20 and (ii) $<100 \%$ of the bases in the read above a Phred quality score of 13 . The raw sequencing data have been deposited in the Sequence Read Archive (SRA) at NCBI.

$3^{\prime}$ RNAseq procedure for V. vinifera. Quality reads were aligned to the $12 x . v 2$ genome assembly of PN40024 and the Vcost.v3 annotation (Canaguier et al. 2017) using the program STAR (Dobin et al. 2013) with default parameters. SAMtools v1.7 was used to sort the alignment records and covert to a BAM format (Li et al. 2009). HTSeq v0.9.1 (htseq-count-f bam-stranded $=$ no) was used to obtain gene-level counts from the resulting BAM files (Anders et al. 2015). DESeq2 was used to perform a likelihood ratio test (LRT in DESeq2) (Anders and Huber 2010). Three design formulas were used to model the gene counts (Table 5). $P$ values generated by DESeq2 were adjusted for multiple testing using the Benjamini-Hochberg procedure (Benjamini and Hochberg 1995). An adjusted $P$ value $\leq 0.10$ indicated that the gene was statistically differentially expressed. The DEGs from the union of the three designs were combined and used in subsequent pathway analyses and visualizations of molecular networks.

Objective cluster analysis. A cluster analysis was performed to determine groups of genes that had similar expression levels. The R package Mfuzz function "kmeans2" was used to perform a kmeans clustering based on the number of centroids provided (Kumar and Futschik 2007). A workflow was devised for objectively choosing the optimum number of centroids, using between six and 15 cluster centroids, inclusively, as follows:
1. For each time point in each cluster, calculate the $\mathrm{L}_{2} \mathrm{FC}$ standard deviation.

2. Calculate the mean of the standard deviations across the five time points for each cluster.

3. Find the median of that value across the clusters in that centroid setting.

4. The centroid with the smallest median value represented the optimum centroid setting because those clusters were grouped more tightly compared with the other centroid settings.

Once the optimum centroid setting was selected, the clusters were ordered by decreasing absolute mean $\mathrm{L}_{2} \mathrm{FC}$ at $24 \mathrm{hpc}$ to identify those clusters enriched for genes differentially expressed during maximum resistance. The gene clusters obtained from this process were then used for pathways analysis. Genes in each cluster were also functionally annotated.

Functional annotation and pathways analysis of DEGs. Functional annotations for genes were determined using the VitisNet knowledgebase (Grimplet et al. 2012). Unique gene identifiers were used to map each to the associated gene ontology term, plant ontology terms, pathways associations, known Arabidopsis thaliana orthologs, and other functional information. The program VitisPathways (Osier 2016) was used to identify biological pathways and molecular functions enriched in each cluster. Enriched pathways for each cluster were determined using 1,000 permutations and a permuted $P$ value $\leq 0.05$. Heatmaps were created in $\mathrm{R}$ v.3.5.3 using the "pheatmap" package showing the shared pathways between the clusters (R Core Team 2017). The color scale for the heatmaps were based on the permutated $P$ value. The DEGs from all gene clusters were also all visualized in Cytoscape (Shannon et al. 2003) using $V$. vinifera molecular networks downloaded from VitisNet 12X (Grimplet et al. 2012) to identify the specific step where each gene fit into its respective pathway. The raw sequencing data have been deposited in the SRA at NCBI and will be released upon publication. Summarized phenotypic data are presented here, and raw data can be requested by contacting the corresponding author.

\section{ACKNOWLEDGMENTS}

We thank X. Xu for her technical support in the RNA extraction process; the Cornell University Biotechnology Resource Center for providing the necessary infrastructure, personnel, and expertise to process the RNA and generate sequence data; M. J. Welser and D. Johnston for providing technical support and propagated biological materials used here; and J. Londo and A. Fennell for providing critical insights regarding the expression analyses and cold-related responses in grapevine.

\section{AUTHOR-RECOMMENDED INTERNET RESOURCES}

Raw sequencing data, SRA at NCBI: https://www.ncbi.nlm.nih.gov/ bioproject/PRJNA281110/

VitisPathways: http://momtong.rit.edu/cgi-bin/VitisPathways/vitispathways.cgi

\section{LITERATURE CITED}

Achuo, E. A, and Prinsen, E. 2006. Influence of drought, salt stress and abscisic acid on the resistance of tomato to Botrytis cinerea and Oidium neolycopersici. Plant Pathol. 55:178-186.

Aćimović, S. G., and Rosenberger, D. 2018. An introduction to the RIMpro apple scab prediction model. Scaffolds Fruit J. 27:1-5.

Anders, S., and Huber, W. 2010. Differential expression analysis for sequence count data. Genome Biol. 11:R106.

Anders, S., Pyl, P. T., and Huber, W. 2015. HTSeq-A Python framework to work with high-throughput sequencing data. Bioinformatics 31:166-169.

Appiano, M., Catalano, D., Santillán Martínez, M., Lotti, C., Zheng, Z., Visser, R. G. F., Ricciardi, L., Bai, Y., and Pavan, S. 2015. Monocot and dicot MLO powdery mildew susceptibility factors are functionally 
conserved in spite of the evolution of class-specific molecular features. BMC Plant Biol. 15:257.

Asalf, B., Gadoury, D. M., Tronsmo, A. M., Seem, R. C., Dobson, A., Peres, N. A., and Stensvand, A. 2014. Ontogenic resistance of leaves and fruit, and how leaf folding influences the distribution of powdery mildew on strawberry plants colonized by Podosphaera aphanis. Phytopathology 104:954-963.

Aust, H., and Hoyningen-Huene, J. V. 1986. Microclimate in Relation to Epidemics of Powdery Mildew. Annu. Rev. Phytopathol. 24:491-510.

Babraham Bioinformatics. 2012. FASTQC, a Quality Control Tool for the High Throughput Sequence Data. Babraham Institute. http://www. bioinformatics.babraham.ac.uk/projects/fastqc

Bahuguna, R. N., and Jagadish, K. S. V. 2015. Temperature Regulation of Plant Phenological Development. Environ. Exp. Bot. 111:83-90.

Barba, P., Cadle-Davidson, L., Galarneau, E., and Reisch, B. 2015. Vitis rupestris $\mathrm{B} 38$ confers isolate-specific quantitative resistance to penetration by Erysiphe necator. Phytopathology 105:1097-1103.

Bates, D., Mächler, M., Bolker, B., and Walker, S. 2015. Fitting linear mixed-effects models using lme4. J. Stat. Softw. 67:1-48.

Benjamini, Y., and Hochberg, Y. 1995. Controlling the false discovery rate : A practical and powerful approach to multiple testing. R. Stat. Soc. 57: 289-300.

Canaguier, A., Grimplet, J., Di Gaspero, G., Scalabrin, S., Duchêne, E., Choisne, N., Mohellibi, N., Guichard, C., Rombauts, S., Le Clainche, I., Bérard, A., Chauveau, A., Bounon, R., Rustenholz, C., Morgante, M., Le Paslier, M. C., Brunel, D., and Adam-Blondon, A. F. 2017. A new version of the grapevine reference genome assembly (12X.v2) and of its annotation (VCost.v3). Genom. Data 14:56-62.

Cao, J., Li, X., and Lv, Y. 2017. Dynein light chain family genes in 15 plant species: Identification, evolution and expression profiles. Plant Sci. 254: 70-81.

Chinnusamy, V., Ohta, M., Kanrar, S., Lee, B. H., Hong, X., Agarwal, M., and Zhu, J. K. 2003. ICE1: A regulator of cold-induced transcriptome and freezing tolerance in Arabidopsis. Genes Dev. 17:1043-1054.

Denancé, N., Szurek, B., and Noël, L. D. 2014. Emerging functions of nodulin-like proteins in non-nodulating plant species. Plant Cell Physiol. 55:469-474.

Dobin, A., Davis, C. A., Schlesinger, F., Drenkow, J., Zaleski, C., Jha, S., Batut, P., Chaisson, M., and Gingeras, T. R. 2013. STAR: Ultrafast universal RNA-seq aligner. Bioinformatics 29:15-21.

Feechan, A., Jermakow, A. M., Torregrosa, L., Panstruga, R., and Dry, I. B. 2008. Identification of grapevine MLO gene candidates involved in susceptibility to powdery mildew. Funct. Plant Biol. 35:1255-1266.

Ficke, A., Gadoury, D. M., and Seem, R. C. 2002. Ontogenic resistance and plant disease management: A case study of grape powdery mildew. Phytopathology 92:671-675.

Golnaraghi, A., Shahraeen, N., and Nguyen, H. D. 2018. Characterization and genetic structure of a Tospovirus causing chlorotic ring spots and chlorosis disease on peanut; comparison with Iranian and Polish populations of tomato yellow fruit ring virus. Plant Dis. 102:15091519.

Gordon, A., and Hannon, G. J. 2010. Fastx-Toolkit. FASTQ/A Short-Reads Pre-Processing Tools. http://hannonlab.cshl.edu/fastx_toolkit/

Grimplet, J., Van Hemert, J., Carbonell-Bejerano, P., Díaz-Riquelme, J., Dickerson, J., Fennell, A., Pezzotti, M., and Martínez-Zapater, J. M. 2012. Comparative analysis of grapevine whole-genome gene predictions, functional annotation, categorization and integration of the predicted gene sequences. BMC Res. Notes 5:213.

Guo, W. L., Chen, B. H., Chen, X. J., Guo, Y. Y., Yang, H. L., Li, X. Z., and Wang, G. Y. 2018. Transcriptome profiling of pumpkin (Cucurbita moschata Duch.) leaves infected with powdery mildew. PLoS One 13: e0190175.

Guy, C., Haskell, D., Li, Q.-B., and Zhang, C. 1996. Molecular chaperones: Do they have a role in cold stress responses of plants? Pages 109-129 in: Plant Cold Hardiness. P. H. Li and T. H. H. Chen, eds. Springer, Boston, MA, U.S.A.

Horváth, I., Glatz, A., Varvasovszki, V., Török, Z., Páli, T., Balogh, G., Kovács, E., Nádasdi, L., Benkö, S., Joó, F., and Vígh, L. 1998. Membrane physical state controls the signaling mechanism of the heat shock response in Synechocystis PCC 6803: Identification of hsp17 as a "fluidity gene". Proc. Natl. Acad. Sci. U.S.A. 95:3513-3518.

Kumar, L., and Futschik, M. E. 2007. Mfuzz: A software package for soft clustering of microarray data. Bioinformation 2:5-7.

Kusch, S., and Panstruga, R. 2017. mlo-Based resistance: An apparently universal "weapon" to defeat powdery mildew disease. Mol. PlantMicrobe Interact. 30:179-189.

Ladwig, F., Stahl, M., Ludewig, U., Hirner, A. A., Hammes, U. Z., Stadler, R., Harter, K., and Koch, W. 2012. Siliques are Red1 from Arabidopsis acts as a bidirectional amino acid transporter that is crucial for the amino acid homeostasis of siliques. Plant Physiol. 158:1643-1655.

Lenth, R. 2018. Emmeans: Estimated Marginal Means, aka Least-Squares Means. R Package Version 1.0. https://cran.r-project.org/web/packages/ emmeans/index.html

Li, H., Handsaker, B., Wysoker, A., Fennell, T., Ruan, J., Homer, N., Marth, G., Abecasis, G., Durbin, R., and 1000 Genome Project Data Processing Subgroup. 2009. The sequence alignment/Map format and SAMtools. Bioinformatics 25:2078-2079.

Lo, K. W. H., Naisbitt, S., Fan, J. S., Sheng, M., and Zhang, M. 2001. The 8$\mathrm{kDa}$ dynein light chain binds to its targets via a conserved (K/R)XTQT motif. J. Biol. Chem. 276:14059-14066.

Londo, J. P., Kovaleski, A. P., and Lillis, J. A. 2018. Divergence in the transcriptional landscape between low temperature and freeze shock in cultivated grapevine (Vitis vinifera). Hortic. Res. 5:10.

Merry, A. M., Evans, K. J., Corkrey, R., and Wilson, S. J. 2013. Coincidence of maximum severity of powdery mildew on grape leaves and the carbohydrate sink-to-source transition. Plant Pathol. 62:842-850.

Mortensen, L. M., and Gislerød, H. R. 2005. Effect of air humidity variation on powdery mildew and keeping quality of cut roses. Sci. Hortic. (Amsterdam, Neth.) 104:49-55.

Moyer, M. M., Gadoury, D. M., Cadle-Davidson, L., Dry, I. B., Magarey, P. A., Wilcox, W. F., and Seem, R. C. 2010. Effects of acute lowtemperature events on development of Erysiphe necator and susceptibility of Vitis vinifera. Phytopathology 100:1240-1249.

Moyer, M. M., Londo, J., Gadoury, D. M., and Cadle-Davidson, L. 2016. Cold stress-induced disease resistance (SIDR): Indirect effects of low temperatures on host-pathogen interactions and disease progress in the grapevine powdery mildew pathosystem. Eur. J. Plant Pathol. 144: 695-705.

Novillo, F., Medina, J., and Salinas, J. 2007. Arabidopsis CBF1 and CBF3 have a different function than $\mathrm{CBF} 2$ in cold acclimation and define different gene classes in the CBF regulon. Proc. Natl. Acad. Sci. U.S.A. 104:21002-21007.

Osier, M. V. 2016. VitisPathways: Gene pathway analysis for V. vinifera. Vitis 55:129-133.

R Core Team. 2017. R: A Language and Environment for Statistical Computing. R Foundation for Statistical Computing, Vienna, Austria. https://www.r-project.org/

SAS Institute Inc. 2019. SAS/STAT software. SAS Institute Inc., Cary, NC, U.S.A. https://www.sas.com/en_us/software/stat.html

Shannon, P., Markiel, A., Ozier, O., Baliga, N. S., Wang, J. T., Ramage, D., Amin, N., Schwikowski, B., and Ideker, T. 2003. Cytoscape: A software environment for integrated models of biomolecular interaction networks. Genome Res. 13:2498-2504.

Small, I. M., Joseph, L., and Fry, W. E. 2015. Development and implementation of the BlightPro decision support system for potato and tomato late blight management. Comput. Electron. Agric. 115: 57-65.

Taiz, L., and Zeiger, E. 2006. Z-scheme of photosynthesis. Page 120 in: Plant Physiology, 4th ed. Sinauer Associates, Sunderland, MA, U.S.A.

Thomas, C. S., Gubler, W. D., and Leavitt, G. 1994. Field testing of a powdery mildew disease forecast model on grapes in California. (Abstr.) Phytopathology 84:1070.

Thomashow, M. F. 1999. Plant cold acclimation: Freezing tolerance genes and regulatory mechanisms. Annu. Rev. Plant Physiol. Plant Mol. Biol. 50:571-599.

Wang, M., Vannozzi, A., Wang, G., Liang, Y. H., Tornielli, G. B., Zenoni, S., Cavallini, E., Pezzotti, M., and Cheng, Z. M. 2014. Genome and transcriptome analysis of the grapevine (Vitis vinifera L.) WRKY gene family. Hortic. Res. 1:14016.

Weldon, B., Gadoury, D. M., and Cadle-Davidson, L. E. 2017. Cold induced disease resistance may explain unexpected stalling of foliar epidemics of hop powdery mildew (Podosphaera macularis). In: Proc. 2017 Am. Phytopathol. Soc. Annu. Meet.

Wiese, J., Wiese, H., Schwartz, J., and Schubert, S. 2005. Osmotic stress and silicon act additively in enhancing pathogen resistance in barley against barley powdery mildew. J. Plant Nutr. Soil Sci. 168:269-274.

Wilcox, W. F., Gubler, W. D., and Uyemoto, J. K. 2015. Introduction. Pages 1-16 in: Compendium of Grape Diseases, Disorders, and Pests, Second Edition. American Phytopathological Society, St. Paul, MN, U.S.A.

Williams, J. C., Roulhac, P. L., Roy, A. G., Vallee, R. B., Fitzgerald, M. C., and Hendrickson, W. A. 2007. Structural and thermodynamic characterization of a cytoplasmic dynein light chain-intermediate chain complex. Proc. Natl. Acad. Sci. U.S.A. 104:10028-10033.

Winterhagen, P., Howard, S. F., Qiu, W., and Kovács, L. G. 2008 Transcriptional up-regulation of grapevine $M L O$ genes in response to powdery mildew infection. Am. J. Enol. Vitic. 59:159-168. 
Xiao, H., Siddiqua, M., Braybrook, S., and Nassuth, A. 2006. Three grape CBF/DREB1 genes respond to low temperature, drought and abscisic acid. Plant Cell Environ. 29:1410-1421.

Xin, H., Zhu, W., Wang, L., Xiang, Y., Fang, L., Li, J., Sun, X., Wang, N., Londo, J. P., and Li, S. 2013. Genome wide transcriptional profile analysis of Vitis amurensis and Vitis vinifera in response to cold stress. PLoS One 8:e58740.
Yamaguchi-Shinozaki, K., and Shinozaki, K. 2006. Transcriptional regulatory networks in cellular responses and tolerance to dehydration and cold stresses. Annu. Rev. Plant Biol. 57:781-803.

Zhu, Q., Gao, P., Wan, Y., Cui, H., Fan, C., Liu, S., and Luan, F. 2018. Comparative transcriptome profiling of genes and pathways related to resistance against powdery mildew in two contrasting melon genotypes. Sci. Hortic. (Amsterdam, Neth.) 227:169-180. 